\title{
(RE)PRODUÇÃO DO HETEROSSEXISMO E DA HETERONORMATIVIDADE NAS RELAÇÕES DE TRABALHO: A DISCRIMINAÇÃO DE HOMOSSEXUAIS POR HOMOSSEXUAIS
}

ELOISIO MOULIN DE SOUZA

Doutor em Psicologia pelo Centro de Ciências Humanas da Universidade Federal do Espírito Santo (Ufes). Professor do Departamento de Administração da Universidade Federal do Espírito Santo. Avenida Fernando Ferrari, 514, Goiabeiras, Vitória - ES - Brasil - CEP 29075-910

E-mail: eloisiomoulin@gmail.com

SEVERINO JOAQUIM NUNES PEREIRA

Doutor em Administração pela Escola Brasileira de Administração Pública e de Empresas da Fundação Getulio Vargas (Ebape-FGV).

Professor do Departamento de Administração e Turismo da Universidade Federal Rural do Rio de Janeiro (UFRRJ).

Avenida Governador Roberto Silveira, s/n, Centro, Nova Iguaçu - RJ - Brasil - CEP 26285-060

E-mail: bill.pereira4@gmail.com

Este artigo pode ser copiado, distribuído, exibido, transmitido ou adaptado desde que citados, de forma clara e explícita, o nome da revista, a edição, o ano, e as páginas nas quais o artigo foi publicado originalmente, mas sem sugerir que a RAM endosse a reutilização do artigo. Esse termo de licenciamento deve ser explicitado para os casos de reutilização ou distribuição para terceiros. Não é permitido o uso para fins comerciais. 
- (RE)PRODUÇÃO DO HETEROSSEXISMO E DA HETERONORMATIVIDADE NAS RELAÇÕES DE TRABALHO •

\section{RESUMO}

Este artigo estudou a possível existência de discriminação no local de trabalho praticada por homossexuais contra homossexuais. Inicialmente foram analisadas pesquisas brasileiras e norte-americanas que envolvem o estudo da discriminação de homossexuais no local de trabalho. Também foram apresentados os conceitos de heterossexismo e heteronormatidade, bem como os seus efeitos sobre a discriminação de homossexuais, além da relação desses conceitos com a concepção de identidade homossexual. A pesquisa foi do tipo qualitativa, e, como instrumento de coleta de dados, utilizou-se um roteiro de entrevista semi-estruturado dividido em dois grandes blocos de perguntas. O primeiro bloco intenta entender a história de vida de cada sujeito e a maneira como ele lida com sua sexualidade no meio social em que está inserido. O segundo bloco está diretamente relacionado com o histórico e a vivência profissional dos trabalhadores. Foram entrevistados oito homossexuais trabalhadores de empresa pública e de economia mista do setor de serviços. As entrevistas foram analisadas por meio da técnica de análise do discurso (AD) desenvolvida por Michel Foucault. Conclui-se que os homossexuais têm preconceitos e discriminam homossexuais no local de trabalho. Verificou-se que a discriminação exercida contra homossexuais é algo presente no discurso dos entrevistados, pois estes materializam preconceitos em atitudes direcionadas a outros homossexuais, como não sair em público com pessoas afeminadas. Isso ocorre porque toda classificação identitária atua como um dispositivo de poder (re)produtor de valores e discursos que manifestam as relações de poder já estabelecidas na sociedade. Verificou-se que, quando os homossexuais entrevistados manifestam forte discriminação e repulsa a outros sujeitos homossexuais que sejam mais afeminados, eles intentam, ao mesmo tempo, um duplo movimento que objetiva: I. reafirmar que a característica presente em todos os homossexuais é a afeminação, característica que faz com que sejam seres inferiores dentro da escala social estabelecida, reforçando, assim, a ideia de identidade homossexual; e 2. que eles, os entrevistados, não são pessoas inferiores, pois não apresentam essa característica identitária. 


\section{PALAVRAS-CHAVE}

Heterossexismo; Heteronormatividade; Homossexuais; Discriminação; Relações de trabalho.

\section{INTRODUÇÃO}

O estudo de grupos socialmente marginalizados, como gays, negros, mulheres, entre outros, não é fácil, porém de extrema relevância para a área de administração, pois a determinados grupos sociais é negado praticamente o status de membros da sociedade (BARBOSA, 2006). No entanto, recentemente, tem ocorrido nos estudos organizacionais brasileiros um crescimento do quantitativo de artigos e pesquisas que analisam a discriminação sofrida por homossexuais no ambiente organizacional. Siqueira, Ferreira e Zauli-Fellows (2006) analisam, por meio de uma pesquisa bibliográfica de nove periódicos internacionais, no período de vinte anos, a identidade e a cultura gay, para compreender a problemática relacionada à discriminação no trabalho em função da orientação sexual. Irigaray (2007a) estudou a política de diversidade implantada no Brasil por uma empresa multinacional do ramo tecnológico e as estratégias de sobrevivência de homossexuais no ambiente de trabalho (IRIGARAY, 2007b). Ferreira e Siqueira (2007) fazem um estudo com o objetivo de analisar os efeitos de ser gay nas organizações contemporâneas, realizando sua pesquisa em empresas públicas, privadas e de economia mista de diversos segmentos de atuação. Eccel e Flores-Pereira (2008) analisam o programa de diversidade voltado para homossexuais em uma livraria.

A discriminação relacionada a homossexuais é, há algum tempo, um assunto considerado relevante pela comunidade científica norte-americana, existindo inclusive revistas científicas específicas sobre o tema, como Journal of Homosexuality. Em função disso, grande parte das pesquisas realizadas sobre a discriminação de homossexuais no local de trabalho são estudos norte-americanos. Dentre esses estudos, vale ressaltar os trabalhos de Herek (I991, I992, I998), Lyons, Brenner e Fassinger (2005), Ragins e Cornwell (2001), Badgett (I995) e Cain (I99I). Normalmente tanto as pesquisas estrangeiras quanto as brasileiras que estudam esse fenômeno intentam retratar a discriminação sofrida pelos homossexuais e não abordam uma eventual discriminação praticada pelos homossexuais. Portanto, este artigo pretende estudar uma possível discriminação exercida pelos homossexuais contra homossexuais nas relações de trabalho. 
Preconceito é qualquer forma de "percepções mentais negativas em face de indivíduos e de grupos socialmente inferiorizados, bem como as representações sociais conectadas a tais percepções" (RIOS, 2007, p. 27-28). O termo discriminação significa a "materialização, no plano concreto das relações sociais, de atitudes arbitrárias, comissivas ou omissivas, relacionadas ao preconceito, que produzem violações de direitos dos indivíduos e dos grupos" (RIOS, 2007, p. 28).

Dessa forma, para estudar a discriminação direcionada a homossexuais por seus pares, faz-se necessário entender aqui como se deu a construção discursiva da homossexualidade, apresentar os conceitos de heterossexismo, heteronormatividade no ambiente organizacional e os estudos que tratam das relações entre identidade e heterossexismo.

\section{A "INVENÇÃO" DA HOMOSSEXUALIDADE}

A homossexualidade, o sujeito homossexual ou, como é mais comumente denominado na sociedade brasileira, o gay são "invenções” do século XIX. Até então, as relações afetivas e sexuais entre pessoas do mesmo sexo eram consideradas sodomia, sendo um comportamento vergonhoso ao qual qualquer pessoa poderia sucumbir. A partir da segunda metade do século XIX, a prática homossexual passava a definir um tipo especial de sujeito e, consequentemente, uma nova categoria social, que viria a ser marcada, estigmatizada e reconhecida sob o nome de homossexual, categorizado, e nomeado, como desvio da norma. Os indivíduos que se encaixassem, ou fossem forçadamente encaixados nessa categoria, passaram a viver em segredo, tendo o medo como norte e sendo obrigados a suportar as dores da segregação social (SILVA, 2006; GREEN, 2000; FOUCAULT, I988).

Ao longo dos anos, muitas vezes a homossexualidade foi definida como uma patologia ou até mesmo como uma perversão. No entanto, deve-se observar que à ideia de homossexualidade concerne um termo que não designa uma realidade em si, mas algo que foi socialmente construído e é fruto de um discurso moral da modernidade. Foucault (I988) afirma que existiu um projeto de iluminação de todos os aspectos do sexo. Criou-se um aparelho que, ao multiplicar os discursos sobre o sexo, visou produzir, ou reproduzir, verdades sobre ele. No século XIX, tal projeto alia-se a um projeto científico, fatalmente comprometido com o evolucionismo e com os racismos oficiais (GAGNON, 2006).

Dessa forma, os mecanismos de poder em relação ao sexo se deslocam da Igreja e da lei para a hegemonia da educação e da ciência. Ocorreu na prática o 
surgimento de uma sciencia sexualis que se produzira a verdade sobre o sexo, sendo o testemunho a técnica mais valorizada nessa produção. A hipótese geral proposto por Foucault (I988) é de que a sociedade não se recusa a reconhecer o sexo, mas, pelo contrário, aciona todo um aparelho para produzir o discurso "verdadeiro e legitimador", que tem como objetivo disciplinatório.

Por meio dessa construção discursiva, foi classificado o normal e o natural como a heterossexualidade, e, em contrapartida, a homossexualidade é classificada como anormal e desvio. Segundo Foucault (I988), a história da sexualidade deve ser desenvolvida e compreendida a partir de uma história dos discursos, que também estaria ligada a relações de poder e dominação. Essa divisão entre homossexuais e heterossexuais fez com que os indivíduos que se classificassem como homossexuais passassem a ser vistos como tendo desvios; sendo, assim, relegados à marginalidade. Isso ocasionou o surgimento de grupos e, consequentemente, de uma cultura homossexual caracterizada por comportamentos, estilos de vida e, principalmente, por uma maneira de viver, sentir, desejar, amar, sofrer e vivenciar as diversas experiências da vida, e não simplesmente uma lei universal da diferença dos sexos (GUIMARÃES, 2004; KATES, 2002; NUNAN, 2003).

No Ocidente, o início do século XX reproduz com grande ênfase o discurso de controle e punição dos vários desvios e vícios relatados anteriormente. No entanto, a história da sexualidade tem grandes mudanças nas quatro primeiras décadas do século XX com um mundo envolto em um turbilhão de mudanças e questionamentos sociais. É nesse contexto que, em I938, Alfred Kinsey (I948) conduziu as suas primeiras entrevistas e iniciou as suas pesquisas sobre sexualidade, concebendo a sua obra - O comportamento sexual do homem - publicada em I948. Na divulgação de seus achados, Kinsey trouxe para a luz a sexualidade, em seu sentido mais alto, revelado abertamente e sem meias palavras por meio da mídia da época (GAGNON, 2006).

Assim como os trabalhos de Kinsey, outros estudos na área das ciências sociais vinham para contestar os rótulos ligados à categoria da homossexualidade, que passa por uma transformação profunda a partir de I950 até I980 (GAGNON, 2006). De certa forma, essa transformação foi consequência do questionamento de vários movimentos sociais, como os defensores dos direitos dos negros, aqueles em prol das liberdades civis, as revoltas estudantis e o movimento feminista, o movimento gay, entre outros. Segundo Gagnon (2006), as ciências sociais tiveram uma grande influência nesse processo ao questionarem os dogmas da psicanálise, que haviam fornecido a justificativa médica da perversão homossexual. Os cientistas sociais informaram que a homossexualidade era socialmente construída pela cultura e pela história, e não por fatores biológicos ou distorções precoces da personalidade. 
Todo esse questionamento sobre a homossexualidade e as pesquisas sociais acerca desse grupo parecem ter de alguma forma acompanhado uma maior liberdade sexual das décadas I970 e I980. Esse clima de maior liberdade e o surgimento, nessa época, dos primeiros grupos gays, de villages e empreendimentos comerciais direcionados para o público gay refletiam uma maior visibilidade e liberdade desses grupos. Estes emigravam para os grandes centros urbanos como Nova York, Toronto, Los Angeles e Rio de Janeiro ou pelo menos essas cidades passaram a ser destinos turísticos e de trocas culturais entre o grupo (KATES, 2002; HASLOP; HILL; SCHIMIDT, I998; ERIBON, 2008).

No Brasil, a homossexualidade teve um tratamento análogo a países como Estados Unidos e Canadá, sendo a homossexualidade vista como doença a ser tratada ou eliminada. Em I89o, o Código Penal brasileiro previa a punição para práticas homossexuais entre homens, mas as referências no texto eram sutis, com utilização de palavras como "atentado ao pudor" e "libidinagem", o que permitia várias interpretações por parte dos juristas (GREEN, 2000).

A forma como a sociedade brasileira via a homossexualidade foi se modificando com o passar dos anos, em especial com o aparecimento da Aids, nos anos i980, que fez com que mais uma vez a sociedade associasse uma doença à homossexualidade e a nomeasse "câncer gay". Apesar disso, a epidemia da Aids também trouxe à tona novas formas de organização social do movimento Gays, Lésbicas, Bissexuais e Transexuais (GLBT) e uma maior visibilidade e discussão desse tema pela sociedade brasileira (PEREIRA, 2004). Embora a maneira de tratar a homossexualidade no Brasil tenha sofrido grandes modificações, o tema ainda é visto com ressalvas pela sociedade e pelo Estado. No Brasil, intolerância, brincadeiras maldosas, homofobia e até violência física estão ainda presentes na realidade dos homossexuais.

\section{RELAÇÕES ENTRE IDENTIDADE DE GRUPO E HETEROSSEXISMO}

O principal intento da construção de identidades sexuais reside na tentativa de tornar as diferenças de sexo algo natural e determinado. Portanto, quando se equaciona a natureza com a heterossexualidade, esta passa a ser institucionalizada como uma norma social, política, jurídica e econômica, seja de uma maneira explícita ou implícita. Nesse aspecto, uma vez institucionalizado, o heterossexismo passa a ser incorporado na cultura e manifesta-se nos discursos diários das pessoas (RIOS, 2007).

Essa naturalização do heterossexual reifica a ideia de que qualquer comportamento que fuja do padrão heterossexual acaba provocando uma problematização 
sobre o próprio modelo, devendo ser coibido, pois põe em risco a harmonia dos papéis sociais definidos em função de gênero e, consequentemente, coloca em perigo toda sociedade. Sendo assim, qualquer questionamento que coloque em dúvida o caráter "natural" e "normal" da heterossexualidade será tratado como uma questão de minorias e colocado à margem social. De forma paradoxal, "esses sujeitos 'marginalizados' continuam necessários, já que servem para circunscrever os contornos daqueles que são normais e que, de fato, se constituem nos sujeitos que importam" (LOURO, 2004, p. 66). Em uma lógica binária (homossexual versus heterossexual), sempre existirá e se admitirá um polo que será desvalorizado, designado como minoria, que, apesar de ser diferente ou desviante, poderá ser "tolerado" pela sociedade. Nessa lógica, torna-se impossível pensar em múltiplas sexualidades, pois o múltiplo é algo que foge a ela (LOURO, 2004). Pocahy (2007) defende que a homofobia e a hierarquização das relações entre homens e mulheres, também denominadas de sexismo, são frutos de uma sexualidade binária que cria um espaço social sexualizado, que atua como sinalizador dos possíveis lugares a serem ocupados.

Pocahy (2007) acredita que o caminho, para que se possa ampliar nossa liberdade, é pela (re)invenção de nós mesmos e pela recusa de classificações e determinações que sejam medicalizantes e moralistas em relação ao nosso corpo, prazer e desejo. Entretanto, o autor afirma que isso só é possível quando se recusa a naturalização das "linhas de inteligibilidade do humano determinadas na amálgama corpo-gênero-sexualidade, no binarismo de corpo e gênero e se refutarmos a banalização da violência expressa em atos, teorias e concepções heterossexistas homofóbicas" (POCAHY, 2007, p. I0). De forma semelhante, Rios (2007, p. 37) admite que a superação da homofobia passa pela desconstrução do binômio hétero/homo, pois a homofobia promove a afirmação da heterossexualidade por meio do repúdio e do combate à homossexualidade, ou seja, "para atacar a homofobia em suas raízes, é preciso suplantar a heterossexualidade e a homossexualidade como identidades sexuais".

Assim, a primeira premissa deste artigo em relação à ideia de gênero é romper com essa concepção binária e identitária que cria fronteiras e limites territoriais em um campo que, na realidade, é heterogêneo e múltiplo. Desse modo, qualquer tentativa de classificação torna-se algo complexo. Classificar as pessoas de heterossexuais, homossexuais, masculino e feminino é reforçar a ideia binária e identitária de sexualidade. Ora, a palavra "gênero" por si só é, em nosso imaginário social, definidora de masculino e feminino e, dessa forma, acaba reforçando a concepção binária de sexualidade, concepção essa que acaba sendo estendida para o binômio homossexual/heterossexual.

A oposição e incomensurabilidade entre os sexos não se manifestam somente em alguns trabalhos científicos sobre gênero, mas, gozando de credibilidade e 
sinônimo de verdade em nossa sociedade, esse discurso científico acaba também se impregnando no dia a dia, nos atos mais simples. Por exemplo, a divisão da sociedade em dois sexos opostos torna-se algo tão marcante em nossa cultura que a cor rosa é considerara como uma cor feminina, e azul, uma cor masculina. Contudo, não se pode afirmar que a ciência é a grande vilã no campo da sexualidade. Sabe-se que ela não é sozinha a produtora de um discurso "verdadeiro", mas que esse discurso é constituído e validado por relações de poder, conforme Foucault (2002) demonstrou ao denunciar a relação existente entre poder e saber. Dentro do próprio campo científico, sempre haverá discursos de resistência aos discursos científicos que usufruem o status de verdade. Para Foucault (I988), existe um dispositivo da sexualidade que é formado pelas relações de poder que a envolvem, as quais são exercidas em todos os níveis, ou seja, esse dispositivo da sexualidade age.

De alto a baixo, em suas decisões globais como em suas intervenções capilares, não importando os aparelhos ou instituições em que se apóie, agiria de maneira uniforme e maciça; funcionaria de acordo com as engrenagens simples e infinitamente reproduzidas da lei, da interdição e da censura: do Estado à família, do príncipe ao pai, do tribunal à quinquilharia das punições cotidianas, das instâncias da dominação social às estruturas constitutivas do próprio sujeito [...] (FOUCAULT, I988, p. 82).

Assim, desnaturalizar e desconstruir o caráter permanente das oposições binárias masculino/feminino e homossexual/heterossexual torna-se fundamental no combate à discriminação, pois somente assim podem-se quebrar as relações de poder que hierarquizam e inferiorizam a mulher e os homossexuais. De acordo com essa afirmação, Scott (I990) salienta que é recorrente nos estudos e na compreensão das sociedades uma análise dicotômica sobre gêneros, na qual homem e mulher são concebidos como polos opostos, tendendo a marcar uma superioridade daquele sobre esta. Assim, desnaturalizar e desconstruir a polaridade rígida das práticas sexuais significa "problematizar tanto a oposição entre eles quanto a unidade interna de cada um" (LOURO, 2008, p. 3I-32). Seguindo essa lógica, o polo heterossexual também contém o homossexual, mesmo que seja de forma postergada e reprimida, e vice-versa. Contudo, também se deve entender cada polo como algo fragmentado e dividido (LOURO, 2008).

Para Swain (200I), o discurso produzido em nossa sociedade atua para mascarar a diversidade que existe no campo sexual, intentando aprisionar essa diversidade em um perfil unívoco, construindo identidades de grupo em razão do sexo biológico. A classificação de homossexuais em minorias reafirma as relações 
hegemônicas de poder no campo de gênero e é uma busca de características que sejam comuns e que possibilitem encontrar uma identidade homossexual (SCOTT, 2005). Sawaia (200I) afirma que a busca de identidade é um dispositivo de poder que age conjunta e concomitantemente como um mecanismo de inclusão e exclusão.

Tendo-se estabelecido as relações entre heterossexismo e identidade de grupo, bem como suas implicações na construção de dispositivos de poder que reforçam a discriminação de práticas sexuais que fogem e escapam do modelo heterossexual, o próximo tópico trará aspectos relacionados ao heterossexismo e à heteronormatividade.

\section{HETEROSSEXISMO E HETERONORMATIVIDADE}

Imaginemos uma organização inserida numa sociedade em que os padrões de comportamentos heterossexuais são os dominantes, em que todos aqueles que se desviem desses padrões são estigmatizados. Essa seria então uma sociedade heteronormativa. Imaginemos agora uma organização inserida nessa sociedade heteronormativa e como tal reproduz os valores e as normas dessa sociedade. Assim, qual seria a influência dessa sociedade construída sobre os moldes do heterossexismo nas relações de trabalho? Quais as suas consequências para os homossexuais? Smith e Ingram (2004), por exemplo, tentam responder a essas questões ao examinarem as relações existentes entre o heterossexismo no trabalho, as interações sociais e o ajustamento de pessoas que são lésbicas, gays ou bissexuais diante dessa realidade, e concluem que o heterossexismo no ambiente de trabalho está positivamente relacionado com a depressão e os distúrbios psicológicos dos sujeitos pesquisados.

O heterossexismo pode ser compreendido como um sistema ideológico que nega, denigre e estigmatiza qualquer forma não heterossexual de comportamento, identidade, relacionamento ou comunidade (Herek, I992). Esse sistema ideológico produz privilégios para pessoas que seguem as normas heterossexuais e exclui aquelas que não as seguem. Esses privilégios incluem direitos civis para casamentos entre heterossexuais, tratamento social não estigmatizado em razão de sua sexualidade, entre outros. No contexto brasileiro, isso pode ser percebido quando aos casais homossexuais se nega o direito ao casamento ou a adoção de crianças.

A construção do heterossexismo inclui preconceitos individuais e institucionais anti-homossexuais, bem como um comportamento anti-gay que pode 
se manifestar em atitudes violentas contra homossexuais (SMITH; INGRAM, 2004). O Federal Bureau of Investigation (FBI) classifica o crime contra gays, lésbicas e bissexuais como o quarto tipo de crime mais comum nos Estados Unidos da América (SMITH; INGRAM, 2004), o que evidencia ainda mais o heterossexismo nas práticas sociais.

Dentre as formas de preconceito externalizadas numa sociedade heterossexista, a homofobia é a que pode resultar em discriminação. Em outras palavras, homofobia "é a modalidade de preconceito e de discriminação direcionada contra homossexuais" (RIOS, 2007, p. 3I). Assim, para que a homofobia exista, deve haver uma distinção que caracterize a homossexualidade como algo ilegítimo em relação ao modelo heterossexual e, dessa forma, deve ser considerada como algo necessário de reparação e de combate, pois a homossexualidade coloca em perigo a estabilidade do binarismo estruturado entre masculino e feminino.

A homofobia é um termo que literalmente significa "medo do igual", sendo usualmente aplicado para expressar o preconceito e a aversão que heterossexuais têm em manter relações de amizade, de afeto e até relações amorosas com pessoas do mesmo sexo, ou seja, é uma palavra que, da mesma forma que o heterossexismo, manifesta o preconceito em relação aos homossexuais. Para Herek (I99I), a homofobia manifesta, pelo menos, três crenças: o preconceito anti-gay é preliminarmente uma resposta relacionada ao medo de enxergar-se como um ser igual aos homossexuais; a homossexualidade é algo irracional e disfuncional; a homossexualidade é uma aberração individual, em vez de uma manifestação de valores culturais.

No entanto, a homofobia também pode vir dos próprios homossexuais, que reproduzem os mesmos preconceitos dos quais são vítimas. Meyer (I995) desenvolve o conceito de "estresse de minorias" para explicar o estresse psicológico vivenciado por grupos estigmatizados. Para o autor, o estresse de minorias é um estado interveniente entre agentes estressores antecedentes e vivenciados sequencialmente em uma cultura sancionada, que categoricamente descreve um determinado grupo com um status inferior, resultante do preconceito e da discriminação social, ou seja, estresse de minoria é o estresse vivenciado por pertencer a um grupo minoritário que é marginalizado e oprimido, podendo provocar uma alienação, uma internalização dos aspectos sociais negativos e uma atitude negativa relacionada com uma determinada orientação sexual. Assim, segundo Meyer (I995), o estresse de minorias é operacionalizado por meio de três componentes: homofobia internalizada, estigma percebido e atitudes preconceituosas.

Nesse raciocínio, homofobia internalizada refere-se a uma visão negativa sobre a homossexualidade que tem sido internalizada por gays, lésbicas e bissexuais. O estigma percebido está relacionado com a opinião de que a pessoa será tratada de forma injusta em virtude de sua sexualidade. Por fim, os eventos 
preconceituosos são as manifestações direcionadas a homossexuais e bissexuais, que são discriminatórias, preconceituosas ou violentas. Os eventos preconceituosos são as ações discriminatórias preconceituosas (MEYER, I995). Para Waldo (I999), a extensão em que as pessoas assumem sua homossexualidade no trabalho está relacionada com o heterossexismo vivenciado no ambiente de trabalho. Waldo (I999) ainda afirma que pessoas que se mostram mais abertas para revelar sua sexualidade no trabalho são as que mais percebem e experimentam situações de heterossexismo.

Para Pino (2007), a heterossexualidade compulsória atua obrigando socialmente as pessoas a se relacionar, amorosa e sexualmente, com pessoas do sexo oposto. Já a heteronormatividade age no sentido de enquadrar todas as relações, mesmo as relações entre pessoas do mesmo sexo, em um binarismo de gênero que pretende organizar as práticas, os atos e desejos, com base no modelo do casal heterossexual reprodutivo. Miskolci (2007) denuncia o pressuposto de heterossexualidade como algo natural e fundamental para a vida em sociedade.

\section{O HETEROSSEXISMO NO AMBIENTE DE TRABALHO}

O ambiente social no local de trabalho é um componente importante para a satisfação no emprego. Para os homossexuais, o maior fator relacionado com a satisfação no trabalho é o grau de abertura que a empresa tem para sua sexualidade no ambiente organizacional. Para Ellis e Riggle (1996), há uma grande relação entre abertura e satisfação com os colegas de trabalho. Além disso, para os pesquisadores, indivíduos que não são completamente assumidos no trabalho estão mais satisfeitos com os salários que recebem e tendem a ganhar mais do que aqueles que são assumidos para os colegas de trabalho e superiores.

Com o objetivo de estudar o heterossexismo no ambiente de trabalho, Smith e Ingram (2004) desenvolveram uma pesquisa que envolveu IoI pessoas gays, lésbicas e bissexuais que moravam e trabalhavam em cidades de tamanho médio nos Estados Unidos. Eles concluíram que o heterossexismo no ambiente de trabalho está positivamente relacionado com a depressão e os distúrbios psicológicos dos sujeitos pesquisados. Lyons, Brenner e Fassinger (2005) utilizam a Theory of Work Adjustment (TWA) para estudar o heterossexismo no trabalho. Os pesquisadores afirmam que a TWA fornece uma abordagem empiricamente suportada para explicar a capacidade de "ajustamento" no trabalho de empregados. A TWA é um dos modelos de desenvolvimento de carreiras mais estudados nos Estados Unidos por psicólogos do trabalho. Assim, a TWA descreve os valores 
correspondentes entre as pessoas e o ambiente na tentativa de predizer a satisfação dos empregados com seus empregos. Portanto, para a TWA, existe uma relação direta entre a pessoa e o ambiente de trabalho. Essa relação pode trazer satisfação ou insatisfação da pessoa com o trabalho desenvolvido (LYONS; BRENNER; FASSINGER, 2005). Nesse raciocínio, Lyons, Brenner e Fassinger (2005) observam que a discriminação informal vivenciada no ambiente organizacional, por meio do heterossexismo presente nas empresas, afeta o ajustamento e a satisfação no trabalho de empregados gays, lésbicas e bissexuais.

Badgett (I995) pesquisou o efeito que a discriminação sexual de homossexuais nas organizações tem sobre os salários deles. O estudo fornece claras evidências de que existem diferenças econômicas entre pessoas com diferentes sexualidades. Homens com um comportamento gay/bissexual ganham entre II\% e $27 \%$ menos do que homens com comportamento heterossexual (o que não significa que não possam ser homossexuais, contudo adotam um comportamento tipicamente heterossexual e não se assumem no trabalho). Apesar de os dados sobre as lésbicas não terem uma consistência estatística, devido à pequena amostra, as mulheres com comportamento lésbico ganham entre $12 \%$ e $30 \%$ menos do que as mulheres com comportamento heterossexual.

Para Badgett (I995), uma das causas de maiores diferenças salariais entre as mulheres com comportamento homossexual é que a amostra de mulheres homossexuais na pesquisa tem uma média de idade bem menor em relação à das mulheres heterossexuais (mulheres homossexuais têm uma média de idade de 34 anos, enquanto as heterossexuais de 39,4 anos), o que tende reduzir os salários em virtude da fase inicial de suas carreiras. Com relação aos homens homossexuais, não há nenhum fator óbvio para reduzir seus salários em relação ao dos homens heterossexuais. Contudo, há uma tendência de os homens gays não estarem localizados nos cargos gerenciais e nos trabalhos que exigem força braçal, mas de estarem trabalhando em ocupações técnicas e relacionadas a serviços.

Nesse sentido, Greenhaus, Parasuraman e Wormley (I990) observam que ocorre discriminação no tratamento no trabalho em relação a homossexuais. A discriminação no tratamento ocorre quando os homossexuais recebem poucas recompensas ou oportunidades de crescimento no trabalho devido a sua condição sexual, tais como não indicação para treinamentos, pouca ou nenhuma promoção e salários menores. Devido a isso, a forma como os homossexuais gerenciam e revelam sua sexualidade no local de trabalho é uma questão delicada para gays e lésbicas que sempre passam por uma relação dicotômica entre querer ser visto como heterossexual ou homossexual (TRIANDIS; KUROWSKI; GELFAND, I994). 


\section{METODOLOGIA DA PESQUISA}

Intentando cumprir os objetivos traçados, efetuou-se uma pesquisa qualitativa com oito trabalhadores que se declararam homossexuais e que trabalham em empresa pública e economia mista, todas ligadas ao setor de serviços. Devido à dificuldade de acesso e identificação de homossexuais para realização das entrevistas, os sujeitos foram selecionados por meio de contatos com entidades sindicais, departamentos de recursos humanos de empresas que atuam no setor de serviços, associações de pessoais e trabalhadores. Solicitou-se também aos sujeitos entrevistados que indicassem outras pessoas para serem entrevistadas.

Dessa forma, as pessoas que indicaram sujeitos para a pesquisa primeiramente entraram em contato com esses sujeitos, solicitando autorização para que os pesquisadores entrassem em contato com eles. Em seguida, as pessoas que os indicaram entraram em contato com os pesquisadores, informando-os da ocorrência, ou não, de autorização para que fossem contatados para serem entrevistados. Os pesquisadores somente entraram em contato com as pessoas que realmente permitiram essa aproximação.

A coleta de dados foi realizada por meio de um roteiro de entrevista semi-estruturado (MCCRAKEN, I988). As entrevistas foram gravadas por processo digital e depois transcritas. O trabalho sobre as transcrições e gravações foi o de identificar categorias importantes para a compreensão das estruturas subjacentes ao discurso. Esse processo levava os autores não apenas a insights sobre os discursos, mas também à releitura e ao aprofundamento da teoria no campo. A cada entrevista, realizavam-se uma nova categorização e uma nova volta à literatura, num processo circular. Dessa forma, uma entrevista alimentava a outra, que gerava novos insights, que alimentavam as entrevistas por vir. Interrompemos o processo no momento em que as entrevistas não forneciam mais informações novas. Os nomes dos entrevistados foram trocados para se manter a confidencialidade deles que receberam as seguintes denominações: Janeiro, Fevereiro, Março, Abril, Maio, Junho, Julho e Agosto. A análise das entrevistas foi realizada utilizando-se a técnica de análise do discurso (AD).

Como existem diversas formas de análise do discurso, utilizou-se a AD francesa, mais precisamente a AD definida segundo os conceitos pós-estruturais de Michel Foucault. Para Foucault (I999, 2002, 2003), o discurso é uma construção social. Sendo assim, o objeto não preexiste ao sujeito e ambos, sujeito e objeto, se constituem mutuamente. Em outras palavras, não existe em Foucault (I999, 2002) nada que possa ser considerado pré-discursivo, pois todo discurso é formado por um contexto social que envolve diversas relações de poder. Dessa forma, para Foucault todo discurso é um discurso histórico, no qual quem fala não é o sujeito, mas a própria história. 
Baseando-se nesses princípios, Foucault (2003) irá analisar o discurso seguindo dois conjuntos. O primeiro conjunto, denominado pelo autor de crítico, coloca em prática o princípio da inversão, caracterizando-se por buscar formas de exclusão, limitação, apropriação do discurso, ou seja, analisar por que interesses e necessidades se formam os discursos, como se modificam e se deslocam e que força esse discurso exerce. O segundo conjunto, denominado por Foucault de conjunto genealógico, tem o intento de pôr em prática os princípios presentes no conjunto crítico: "como se formaram, através, apesar, ou com o apoio desses sistemas de coerção, séries de discursos; qual foi a norma específica de cada uma e quais foram suas condições de aparição, de crescimento, de variação" (FOUCAULT, 2003, p. 6o-6I). Para entendermos melhor como o conjunto crítico e o genealógico se articulam, devemos entender como Foucault percebe alguns conceitos, entre eles se destacam: acontecimento discursivo; enunciado; prática discursiva; formação discursiva; ruptura.

Para Foucault (I999, 2002), o som vocal não é o único elemento que deve ser levado em consideração na análise do discurso. A enunciação pode ocorrer de diversas maneiras, não se limitando apenas ao que é dito por intermédio da voz. Expressões faciais, intervalos de silêncio, sinais corporais, forma de se vestir, tom de voz, arquitetura de um ambiente, entre outros elementos, também são considerados formas de enunciação. Além disso, todo enunciado é uma produção social, cultural e histórica.

Para Foucault (2003), o discurso é algo descontínuo, uma ruptura, não apresenta uma linearidade ou unicidade. Assim, os discursos não afirmam uma identidade, como acreditam as abordagens estruturalistas, mas uma fragmentação do sujeito. Nesse sentido, buscou-se neste trabalho analisar nos discursos dos entrevistados essa heterogeneidade e descontinuidade dos discursos e a fragmentação do sujeito. Assim, não se acredita que os discursos dos homossexuais tenham identidade, centralidade e unicidade, pois eles manifestam enunciados que podem até ser mesmo antagônicos e contrários a sua orientação sexual, por exemplo. Uma vez apresentados os principais aspectos da metodologia utilizada neste trabalho, o próximo tópico visa trazer uma caracterização dos entrevistados.

\subsection{CARACTERIZAÇÃO DOS ENTREVISTADOS}

Foram analisados os discursos de oito trabalhadores, com idade variando de 4I a 53 anos, concentrando-se a maioria deles na faixa etária entre 40 e 50 anos, apresentando tempo de trabalho que oscila entre oito anos até 30 anos, tendo boa parte deles entre 20 a 30 anos de trabalho no setor de serviços, no qual apenas dois trabalhadores não possuem nível superior. Desses trabalhadores, quatro ocupam função gerencial, e os demais não exercem nenhum cargo comissionado 
nas empresas em que trabalham. Todos os pesquisados quando questionados em relação a sua sexualidade afirmaram ser homossexuais.

A partir dos 7 anos, Janeiro percebeu o despertar de sua orientação sexual. Apaixonou-se por seu vizinho que tinha a mesma idade dele, e, em razão desse sentimento, seu amigo não conseguia sair de sua cabeça. Janeiro frequenta apenas boates gays e não gosta de saunas e bares gays, contudo salienta que, quando era mais novo, frequentava com maior assiduidade boates gays, atualmente tem diminuído bastante a sua frequência. Fevereiro sentia desejos homoafetivos desde sua infância e informou que sua mãe e duas irmãs sabem sobre sua orientação sexual. O pesquisado relatou que frequenta somente saunas gays e cinemas eróticos, mas que não gosta de boates e festas gays. Fevereiro sempre teve relacionamentos homoafetivos de longa duração. Seu primeiro relacionamento durou nove anos, o segundo II anos e atualmente namora um rapaz há três anos e meio. Março informou que conversou com sua família de forma explícita sobre sua orientação sexual e que todos sabem sobre ela. Ele percebeu que tinha desejos homoeróticos por volta dos seus 4 anos de idade, quando seu pai o levou a um estádio para assistir a um jogo de futebol, pois o que mais chamava a atenção de Março no estádio de futebol não era o jogo em si, mas os homens que ali estavam. Março vive em uma relação estável há aproximadamente três anos com outro rapaz.

Abril acredita que sua família sabe sobre sua orientação sexual, apesar de nunca ter conversado com eles sobre isso. Desde cedo sentia desejo por outro homem só que o reprimiu até os seus 33 anos. Abril gosta de ir a boates, bares, saunas e festas gays. Contudo, ele informou que prefere viver relacionamentos amorosos estáveis a procurar encontros casuais com outros homens. Maio acredita que sua família saiba sobre sua orientação sexual, apesar de nunca ter conversado com eles de forma explícita. Somente na sua adolescência começou a sentir desejos homoafetivos. Junho entende-se como homossexual desde que nasceu. Não vai a saunas, bares ou boates gays; frequenta apenas e de forma esporádica festas gays, que denomina de festas Gays Lésbicas e Simpatizantes (GLS). Frequenta essas festas exatamente por considerar que as pessoas que vão a elas não são exclusivamente homossexuais. Junho exerce sua vida sexual através de namoros e relatou que viveu três casamentos homossexuais.

Apesar de Julho não ter conversado de forma clara e explícita com seus familiares sobre sua orientação sexual, ele acredita que seus familiares sabem sobre ela. Afirmou que começou a sentir desejos homossexuais quando estava cursando o ensino médio. Ele não frequenta festas, bares, saunas ou boates gays e prefere exercer a sua vida sexual por meio de relacionamentos estáveis, relatando que viveu recentemente um casamento homoafetivo de I2 anos. Agosto acredita que todos os seus familiares sabem sobre sua homossexualidade, apesar de só ter conversado sobre sua sexualidade de forma aberta com sua irmã, cunhado 
e sobrinhos, evitando falar sobre o assunto com seu pai. Ele afirmou que tem desejos homoafetivos desde sua infância. Contudo, seu primeiro contato sexual com um homem só ocorreu quando tinha 25 anos. Agosto não frequenta bares, boates, festas ou saunas gays, preferindo ir a locais que considera heterossexual, além de pubs e confrarias sociais nas casas de seus amigos. Sobre sua vida sexual, ele prefere relacionamentos duradouros e estáveis, demonstrando uma aversão a casos esporádicos.

\section{A AVERSÃo AO ESTEREÓtIPo FEMININO}

Quando os entrevistados foram questionados se manteriam uma relação profissional e social mais próxima com pessoas que fossem afeminadas, surgiu recorrentemente nos discursos deles uma verdadeira aversão ao homossexual com trejeitos femininos, já que eles evitam qualquer contato social com pessoas afeminadas, tanto no trabalho quanto na vida social, como ilustram as passagens discursivas. Segundo Maio, "com certeza, quando você vai em alguns ambientes, por exemplo, você vai num ambiente familiar, ambiente de trabalho com um amigo muito efeminado, isso te atrapalha um pouco. Você fica meio constrangido de levar, né?". Agosto salienta que "Homem querer ser mulher. Ridículo. Não concordo. Eu sou, e eu uso da discriminação até. Eu me afasto dessas pessoas". Junho esclarece que homossexuais têm muito preconceito de outros homossexuais, principalmente dos afeminados:

[...] há muito mais preconceito entre homossexuais do que dos heterossexuais contra os homossexuais. E quanto mais efeminado é o homossexual, mais vítima de preconceito ele é. Então assim, na minha opinião, o preconceito contra o homossexual aumenta na medida que ele se torna mais efeminado.

\section{De acordo com Março:}

A demonstração exagerada do que você é, da sua condição sexual. Acho que não no trabalho só. Mas em qualquer lugar da vida, você não tem que tá levantando bandeira e eu realmente odeio "veadinhos", odeio "bichinhas", odeio aquelas coisinhas que querem mostrar a mamãe: eu sou "veado" e daí? Sabe, que já tem cara de "veado", se veste como "veado", fala como "veado" e ainda quer mostrar mais ainda que são "veados”. Isso realmente até eu discrimino. 
Esse preconceito também surge no discurso de Abril, que se vê como uma pessoa "discreta" no trabalho, ou seja, alguém que segue o padrão masculino heterossexual no ambiente de trabalho. Ele afirma que não gosta de relacionar-se profissional ou socialmente com pessoas afeminadas. Essa categorização entre os comportamentos femininos e masculinos também é ilustrada por Fevereiro, que afirma que só gosta de namorar pessoas "heterossexuais" e que não se relaciona com homossexuais. É interessante observar como os sujeitos entrevistados reproduzem a estigmatização e o preconceito social no ambiente de trabalho. Para eles, homens homossexuais com comportamentos masculinos heterossexuais são normais e os com comportamentos femininos são anormais, logo rejeitados (FOUCAULT, I984).

Aliás, a rejeição a homossexuais que externalizam o estereótipo do gay feminino é algo que está presente em todas as falas dos entrevistados. Isso parece acontecer exatamente pela visão identitária de grupo reificada nas práticas cotidianas, em que a classificação de alguém como pertencendo a um grupo faz com que os atributos utilizados para definir a identidade desse grupo sejam também atribuídos a todos os seus integrantes. Assim sendo, a afeminação é considerada como um atributo definidor e essencial de todos os homossexuais, passando a ser vista como uma das principais características identitárias do grupo homossexual. Com isso, os próprios homossexuais consideram essa característica, a afeminação, como algo universal e necessária para definir alguém como homossexual. Em resumo: discriminando quem tem traços afeminados no trabalho, classificando homossexuais como mais promíscuos que heterossexuais, afirmando que normal é o heterossexual, incorporando atitudes masculinizadas em demasia no ambiente de trabalho, consertando sua forma de falar e andar, agindo de forma discreta, chamando os homossexuais de "veadinhos" e utilizando a palavra "normal" para definir as pessoas heterossexuais, os homossexuais entrevistados incorporaram em seu discurso boa parte dos preceitos e preconceitos heterossexistas existentes em nossa sociedade (HEREK, I99I). Assim, estão manifestando que também têm condutas discriminatórias relacionadas a homossexuais no trabalho, no momento em que materializam esse preconceito em atitudes comissivas ou omissivas direcionadas a homossexuais afeminados no trabalho.

Além disso, outro fato chama a atenção e reforça esse mundo homossexual construído a partir de preceitos heterossexuais: a importância da definição dos papéis sexuais. As pessoas que exercem um papel ativo nas relações homoafetivas consideram-se como "menos homossexuais" do que os passivos. Alguns dos entrevistados até consideram os ativos como não homossexuais, que é o caso de Maio. Assim, ao acreditarem que cabe apenas à mulher exercer papel passivo nas relações sexuais e ao homem o papel ativo, os homossexuais transferem para suas fronteiras essas crenças e, da mesma forma que a mulher é desvalorizada na 
sociedade, desvalorizam os afeminados exatamente por verem neles uma extensão da mulher (PINO, 2007).

O que chama a atenção é que muitos dos entrevistados têm comportamentos culturalmente tidos como afeminados, apesar de não se enxergarem com tal característica. Dessa forma, mesmo tendo comportamentos afeminados, reproduzem o discurso heterossexista preconceituoso e materializam esse preconceito em atos discriminatórios contra seus pares no trabalho e contra si mesmos, demonstrando que os entrevistados não são sujeitos autônomos na produção discursiva e que todo discurso é marcado por rupturas e descontinuidades; o discurso é algo fragmentado, histórica e socialmente construído por relações de poder, conforme salienta Foucault (2002, 2003).

Portanto, a aversão a pessoas afeminadas relatada pelos entrevistados parece ocorrer pelo seguinte motivo: andar com pessoas afeminadas dá visibilidade a sua condição que, conforme descrita por Rios (2007), não possui nenhum marcador corporal que indique que ele seja homossexual, podendo, assim, passar despercebido. Desse modo, quando o sujeito tem ao seu lado uma pessoa afeminada, a afeminação do outro, socialmente vista como um dos principais indicadores de homossexualidade, passa a denunciá-lo, deixando-o descoberto.

Assim, os entrevistados, para serem aceitos no trabalho e diminuírem atitudes preconceituosas e discriminatórias, valorizam e tentam adotar um comportamento masculinizado à la heterossexual (PINO, 2007), evitando ser uma pessoa afeminada para não dar na pinta que é gay. Julho salienta que "É muito mais gostoso você ser discreto do que você ser aberto". Apesar de muitos deles tentarem camuflar traços afeminados, a maioria não consegue atingir seu intento. Desse modo, o problema é desviado para outro campo, não se concentrando no fato de ser gay ou não, mas sim de como é a percepção do seu comportamento pelos outros no dia a dia, ou seja, se suas condutas são masculinas ou femininas. Portanto, para não serem considerados homossexuais por seus colegas de trabalho, os entrevistados estabelecem um código de conduta fundamentado na discrição. Para eles, ser "discreto" significa adotar um comportamento masculino heterossexual no trabalho e relacionar-se nesse ambiente apenas com pessoas que sejam discretas, conforme Julho afirma ao ser interrogado sobre as pessoas com quem mantém um relacionamento de trabalho mais estreito: "são pessoas totalmente discretas". Aliás, Abril chega a afirmar que as pessoas com quem mais interage no trabalho são pessoas "normais", salientando que, para o entrevistado, a palavra "normal" significa que se relaciona com pessoas heterossexuais, o que demonstra que ele mesmo enxerga os homossexuais como anormais, um desvio. Abril, ainda, afirma que "odeia veadinhos e bichinhas, odeia pessoas que têm cara de veado e se vestem como veados". 
Dentre os comportamentos valorizados no código de conduta estabelecido pelos entrevistados, a vestimenta, a forma de falar e até aspectos culturais e socioeconômicos são considerados elementos de distinção. Janeiro salienta que ser discreto "é um lado de postura, sem sair gritando por aí, dando gritinhos. Felizmente, existe homossexual bom e existe o homossexual perverso", classificando inclusive como perversos os homossexuais que não são discretos no trabalho. Março afirma que "nada contra, mas eu também prefiro manter certa distância. [...] não é discriminação, mas infelizmente tem umas que eu vejo que elas forçam, ela força a voz e começa a dar gritinho, é o famoso falsete. Eu particularmente não gosto. Eu sou contra isso". Fevereiro enuncia que o que distingue no trabalho o afeminado do gay discreto é "Primeiro pela indumentária, pela forma de se vestir. Pelos gritinhos, é o famoso refrão 'veadinho pão com ovo'”. A expressão "veadinho pão com ovo" significa para Fevereiro:

[...] aquele que usa marca de roupa, usa sapatos caros, usa óculos da moda, usa coisas da moda, usa várias e várias marcas e chega em determinada festa e começa a conversar não sobre [...] o pequeno príncipe [...]. Mas fica se expondo, é um verdadeiro outdoor, expondo mercadoria, sendo que lá fora tá devendo deus e o mundo e não pode bancar aquilo.

Todo esse código de conduta na busca pela discrição no trabalho revela o medo de serem discriminados. Por exemplo, quando perguntado se existe algum benefício por não ter assumido sua orientação sexual no trabalho, Julho respondeu que o maior benefício é "Não sofrer discriminação, pelos menos direta”. Março afirma que "Sendo gerente, a gente tem, sente um pouco com medo da discriminação dos funcionários e de clientes. Então, você não pode, eu acho que, eu, pelo menos, me sinto inibido de mostrar a minha homossexualidade pras pessoas".

Contudo, apesar das estratégias utilizadas pelos entrevistados para evitarem a discriminação direta, eles são alvos de discriminações indiretas, sendo estas as que mais incomodam os entrevistados. Para eles, as principais formas de discriminações indiretas que sofrem no trabalho ocorrem por meio de piadas, dificuldade de crescimento na carreira e exclusão do convívio social com os demais colegas de trabalho.

Todos os entrevistados evidenciaram as piadas como sendo a forma mais comum de discriminação no trabalho. Em relação às piadas, Fevereiro enfatiza que os homossexuais são representados de forma caricata:

Nunca é como a maioria dos homossexuais é, né? A maioria dos homossexuais não são caricatos. Então, o que a sociedade vê são os homossexuais caricatos, efeminados e geralmente ele é tratado, ele é visto nessa forma na piada, nos comentários. 
Agosto também evidencia a forma caricata das piadas: "Geralmente, é muito, acho que é um pouco uma figura caricata. Uma figura feminina demais ou eu acho que é diminuindo a pessoa, por ser homossexual". Julho, além de acrescentar que não só homossexuais são discriminados por meio de piadas, mas também negros, considera normal que homossexuais e negros sejam alvos de piadas: "Fazem. Não só comigo, mas com todo mundo. Você entendeu? Faz piadas comigo e também com as outras pessoas que não são homossexuais. Porque é o normal, tanto com homossexuais, como com negros".

A dificuldade de crescimento na carreira é um fato para os trabalhadores entrevistados, mesmo para aqueles que conseguiram ocupar cargos gerenciais. Quando questionado se o fato de ser homossexual afeta de alguma forma o crescimento na empresa, Maio respondeu veementemente: "Eu acredito que sim". Abril afirma que um dos prejuízos no trabalho que percebeu pelo fato de ser homossexual é que "poderia hoje estar assumindo um cargo de gerência dentro do banco", se não fosse homossexual. Para Fevereiro, existem mais oportunidades de crescimento na carreira para heterossexuais do que para homossexuais.

Semelhantemente às piadas sobre homossexuais, a dificuldade de crescimento na carreira aparece presente na fala de todos os entrevistados (GREENHAUS; PARASURAMAN; WORMLEY, I990). Contudo, essa dificuldade se manifesta de duas formas: não conseguir ocupar função gerencial e ocupar funções gerenciais com status inferiores em relação às atividades das demais funções gerenciais existentes. Abril, Maio e Janeiro revelaram que, apesar de a maioria expressiva deles ter mais de 20 anos de carreira nos bancos onde trabalham, nunca ocuparam função gerencial. Julho chegou a ocupar função gerencial, mas não conseguiu permanecer no exercício da função gerencial. Todos os entrevistados que ocupam funções gerenciais, Fevereiro, Março, Junho e Agosto, demoraram mais de uma década para conseguir promoção gerencial dentro dos bancos. Março demorou I3 anos para conseguir ocupar uma função gerencial. Fevereiro, Junho e Agosto, respectivamente, só conseguiram se tornar gerentes com I9, I8 e i6 anos de trabalho na mesma empresa.

Um dos fatores que os entrevistados relacionam à dificuldade de promoção nos bancos é a exclusão deles do convívio social promovido pelos grupos informais de trabalho. Em relação a esse aspecto, Janeiro salienta que a dificuldade de crescimento na carreira de homossexuais ocorre

[...] pelo preconceito e pelo, eu acho que você crescer dentro da empresa, além de demonstrar competência e tudo, mas sempre tem o lado da amizade, da sua [...]. É do seu convívio com as pessoas diretamente superiores. E isso te prejudica se você não tem esse convívio. 
Março afirma que os colegas de trabalho são "preconceituosos porque eles buscam uma forma de... de autodefesa. Eles tentam chegar a se distanciar de você". Julho enfatiza que são os grupos informais de trabalho que evitam os homossexuais, para ele a dificuldade de crescimento está nos "grupinhos": "Eu sempre condeno esse lance de grupinhos. Eu acho que é falta de respeito para com as diversidades. Sabe, eu não concordo". Maio ainda acrescenta que, além da falta de socialização com os demais colegas de trabalho, a preocupação com a imagem da empresa é um fator que também afeta o crescimento na carreira: "Pelo convívio social disso daí. Eles acham que os homossexuais vão denegrir a imagem daquela empresa". Sobre a relação entre convívio social e crescimento na carreira, Fevereiro salienta o seguinte:

Desde a época no banco, você vê as pessoas com ascensão, as pessoas que têm convívio com gerentes, com as pessoas de escala mais alta e que são essas que têm aquela roda de amigos pra beber no bar, pra jogar um futebol, e que você não tem esse convívio com essa pessoa. Então, você vê que você fica pra trás, né? Que você não tem essa disponibilidade, esse convívio com eles. Então, acho que atrapalhou bastante.

Todos os entrevistados, sem nenhuma exceção, diante da pergunta sobre o que caracterizaria uma pessoa como heterossexual, responderam a essa questão sem atribuir nenhuma característica física, genética, biológica e sexual que classifique uma pessoa como heterossexual. Nenhum deles, por exemplo, afirmou que manter relações sexuais com mulheres é uma característica de um homem heterossexual. Existem duas explicações para isso: primeiramente, atravessados pelo pensamento heterossexista, passam a compreender o heterossexual como "normal" e, ao considerarem o heterossexual como padrão "normal" de comportamento, naturalizam o modelo heterossexual (PINO, 2007; FOUCAULT, I988; LOURO, 2004) e contribuem para que os heterossexuais passem despercebidos e sejam vistos como destituídos de características que os marquem, exatamente por não terem nenhum traço considerado como desviante. Segundo, esse movimento também demonstra que os entrevistados acreditam que o que difere uma pessoa homossexual de uma heterossexual são características culturais e não características biológicas que definem o homem e a mulher.

A cultura como constituidora da sexualidade é um fenômeno já relatado por Foucault (1984, I985, I988). Isso pode ser confirmado nas respostas dos entrevistados. Para eles, o que caracteriza um heterossexual são os seguintes traços: machismo, hipocrisia, homofobia, uso de expressões e gestos (coçar o "saco", "mandar a pessoa tomar no cu", "chamar uma mulher de gostosa” em público 
e outros), jogar futebol e falar sobre futebol, olhar a "bunda" de uma mulher quando ela passa, falar sobre mulher e dizer que "transa" com muitas mulheres para demonstrar uma vida sexual ativa. Aliás, Março e Abril chegam até a afirmar que não veem nenhuma marca que possa definir o que seja heterossexual.

De todos os entrevistados, Julho e Abril foram os que manifestaram de forma clara e evidente discriminação em relação a pessoas que não têm práticas sexuais com o mesmo sexo. Para Julho, os heterossexuais têm medo dos homossexuais no trabalho pelo fato de estes serem mais competentes. Assim, Julho acredita que os homossexuais são extremamente competentes no campo profissional, enquanto os heterossexuais não são. Julho acredita em uma superioridade homossexual em termos de competência. Abril acredita que a maioria dos homens heterossexuais é composta de pessoas de baixo nível cultural e sem educação nas relações pessoais. Ele faz uma forte crítica aos homens que não desenvolvem aspectos culturais, exatamente por considerar que é muito difícil manter um diálogo com eles em função disso. Além da inferioridade cultural, os heterossexuais também apresentam uma forma de se comportar, expressar e comunicar considerada "sem educação" por Abril, principalmente no trato com as pessoas no ambiente de trabalho.

\subsection{NEM TUDO É PERMITIDO ABAIXO DA LINHA DO EQUADOR}

Existe no imaginário da população de que tudo é permitido abaixo da linha do Equador, crença expressa na obra de Green (2000). Entretanto, além dos dias de carnaval e dos eventos GLBT promovidos em alguns centros urbanos em datas específicas, qualquer tentativa fora desses momentos para quebrar as fronteiras entre masculino e feminino abaixo da linha do Equador não é algo tão simples e liberado como alguns pensam ser (TREVISAN, 2000).

A análise do discurso dos informantes mostrou que existe uma "regra de conduta" de como os gays devem se comportar para tentar aumentar sua aceitação no ambiente de trabalho e evitar discriminação, como o fragmento do discurso do entrevistado Agosto ilustra:

Eu sou até um pouco sisudo na forma de expressar. Eu acho que essa postura que eu tenho é devido a minha sexualidade. Por ser homossexual, automaticamente eu encaro de uma forma assim, eu tenho que ter recursos maiores que os demais.

Assim, ocorre, no contexto social analisado, algo semelhante ao que Foucault (I984) analisou na sociedade grega antiga, na qual, apesar de toda liberalização e função social existente das relações homoafetivas, existiam regras de 
conduta que funcionavam para regular o exercício dessas práticas. Vale salientar que as regras sociais aqui estabelecidas não são as mesmas demonstradas por Foucault (I984).

A análise do discurso dos informantes parece ilustrar claramente a hierarquização interna entre os gays. Esse ponto vai ao encontro das características culturais brasileiras, em que a sociedade é altamente hierarquizada em razão da sexualidade de seus membros. Assim, existe toda uma hierarquia que estipula a ordem de importância e as expectativas sobre o papel que cada um tem de exercer na sociedade, sendo esse papel algo fortemente relacionado com a orientação sexual das pessoas (GREEN, 2000). Em função dessa hierarquia, serão atribuídos os discursos e as atitudes esperados do homem e da mulher na sociedade, segundo um modelo heterossexual de sociedade. Esses discursos também são reproduzidos entre os gays que estipulam as atitudes e os comportamentos "aceitáveis" baseados entre os masculinos (aceitos) e femininos (rejeitados).

O interessante é que, apesar de os entrevistados habitarem um espaço fora desse esquadrinhamento e a todo o tempo subvertê-lo, eles tentam criar um comportamento de regras e de condutas que tem como espelho e guia os mesmos modelos e padrões que subvertem, conforme demostrado na seção anterior. Ou seja, os homossexuais criam um mundo paralelo ao mundo heterossexual que a todo o momento referencia e reafirma o heterossexual como padrão e "normal". Existem uma naturalização do modelo heterossexual pelos homossexuais e uma tentativa de estabelecer regras de funcionamento similares às do heterossexismo. Esse fenômeno, conforme já descrito por Pino (2007), ilustra a heteronormatividade sendo reproduzida no ambiente de trabalho. Assim, o indivíduo não só é estigmatizado e discriminado pelos heterossexuais, mas também pelos próprios homossexuais, que demonstram uma forte aversão e preconceito ao estereótipo do gay feminino.

Como ilustrado anteriormente, parece ficar clara a existência da heteronormatividade (PINO, 2007) e também que os homossexuais entrevistados são tão heterossexistas quanto algumas pessoas consideradas heterossexuais. Dessa forma, os próprios homossexuais elegeram e acreditam que o normal é ser heterossexual e, tendo estabelecido esse princípio, passam a defender e a criar um mundo paralelo, a moda heterossexual, no qual imitam as regras e as crenças contidas no heterossexualismo para que, assim, sejam aceitos. Em outras palavras, o heterossexismo não é uma atitude exclusiva de pessoas culturalmente consideradas heterossexuais. Tal fato pode ser confirmado tendo-se como exemplo o entrevistado Fevereiro. Fevereiro exagera tanto nos traços que afirmam uma masculinidade heterossexual, ou melhor, uma hipermasculinidade. Tenta a todo o momento demonstrar, por meio de seu corpo e gestos, que é um homem "normal" segundo os ditames heterossexuais definidos que caracterizam o "homem de verdade". 


\section{CONCLUSÃO}

Diante do exposto, uma questão emerge: por qual motivo estariam os próprios homossexuais discriminando os "iguais" (homossexuais) de forma muito mais acentuada do que a discriminação vinda dos "diferentes" (heterossexuais)? A resposta para essa questão depende de uma análise complexa dos dispositivos de poder utilizados para hierarquizar os grupos sociais.

Foucault (2004) afirma que toda classificação é uma relação de poder. Nesse sentido, a criação no imaginário social de que existem dois grupos que agregariam em torno de si mesmos todas as possibilidades de exercício sexual é um mecanismo de classificação que se fundamenta na ideia de identidade. Assim, tanto o homossexual quanto o heterossexual passam a ser definidos por meio de características que seriam universais e estariam presentes em qualquer um dos sujeitos que pertencem a um desses grupos. Dentro dessa lógica, por exemplo, uma das características consideradas universais no homossexual é a sua suposta feminilidade.

Entretanto, qualquer classificação identitária é uma relação de poder que opera pela exclusão. Aliás, toda relação de poder é um mecanismo de exclusão (FOUCAULT, 2004). Sendo assim, a classificação das pessoas em heterossexuais ou homossexuais seria um dispositivo de poder que produz uma hierarquia social, em que o heterossexual é visto como superior e o homossexual como inferior nessa escala. Contudo, o discurso dos entrevistados é algo produzido pelas relações de poder, e o sujeito que fala apenas manifesta essas relações que o constituem por meio dos processos de subjetivação. Essas relações de poder que atuam em rede nos territorializam, desterritorializam e reterritorializam. Portanto, os homossexuais também são investidos pelas relações de poder hegemônicas, que também produz neles um discurso discriminatório em relação aos outros homossexuais.

Quando os homossexuais entrevistados manifestam uma forte discriminação e repulsa a outros sujeitos homossexuais que sejam mais afeminadas, eles intentam, ao mesmo tempo, um duplo movimento: I. reafirmar que a característica presente em todos os homossexuais é a afeminação, característica que faz com que sejam seres inferiores dentro da escala social estabelecida, reforçando, assim, a ideia de identidade homossexual; e 2. que eles, os entrevistados, não são pessoas inferiores, pois não apresentam essa característica identitária. A repulsa à afeminação é tão forte nos pesquisados que muitos deles, mesmo tendo um comportamento culturalmente definido como feminino, preferem não se ver como possuidores de tal característica, movimento feito pelos entrevistados para que possam ver a si mesmo como "normais". 
Assim, conforme Pocahy (2007) salientou, para quebrar a discriminação se faz necessário recusar as classificações e determinações relacionadas ao corpo, prazer e desejo. Essas classificações só reforçam o heterossexismo e a heteronormatividade (PINO, 2007), independentemente da prática sexual exercida por uma pessoa. Rios (2007) também acredita que o fim da homofobia ocorre pela desconstrução do binômio hétero/homo. Entretanto, a homofobia está presente nos homossexuais, não sendo um comportamento exclusivo de heterossexuais. Portanto, o fim da discriminação passa pela desnaturalização e desconstrução da oposição binária/identitária entre homossexuais e heterossexuais.

Aliás, a discriminação que os homossexuais entrevistados têm para com homossexuais manifesta exatamente esse mecanismo que, ao mesmo tempo que inclui o indivíduo como pertencente a um grupo, também o exclui e o discrimina exatamente por ter as características do grupo a que pertence. Assim, a identidade é uma relação de poder em que as significações hegemônicas acabam excluindo as não hegemônicas. Ao se estabelecer a diferença entre duas identidades, tende-se a incluir e valorizar o que é considerado hegemônico e a desvalorizar e excluir aquilo que é considerado minoria, com o principal intuito de preservar a harmonia social e evitar o conflito.

Conclui-se que os próprios trabalhadores entrevistados manifestam preconceito e forte discriminação contra outros homossexuais, principalmente contra pessoas que tenham comportamentos afeminados. Além de apresentarem atos discriminatórios contra os seus pares, manifestaram toda uma regra de conduta baseada no heterossexismo que serve para regular e "normalizar" os comportamentos homoafetivos (PINO, 2007). Em outras palavras, o heterossexismo não está presente apenas em pessoas culturalmente classificadas como heterossexuais, mas também é uma norma socialmente construída pelas relações de poder que também está presente naqueles que, a princípio, estariam subvertendo os padrões heterossexuais de comportamento.

\section{(RE)PRODUCTION OF HETEROSEXISM AND} HETERONORMATIVITY IN LABOR RELATIONS: THE DISCRIMINATION AGAINST HOMOSEXUALS BY HOMOSEXUALS

\section{ABSTRACT}

This article studied whether there is a sexual-orientation bias on the discriminatory acts committed by homosexuals in their workplace. We tackled our results with previously published research findings regarding discrimination against 
homosexuals in the workplace conducted in Brazil and in the U.S.A. Furthermore, we discussed the concepts of heterosexism and heteronormativity describing their effects on the homosexual' discrimination and their correlations with homosexual identity. The research design was qualitative. We collected data using a script for a semi-structured interview divided into two blocks of questions. The first block attempts to understand the life history of each subject and the way he deals with his sexuality in the social environment in which it operates. The second block is directly related to the professional history and experience of the workers. The questions examined discriminatory acts practiced by homosexuals against homosexuals. We interviewed eight workers of the service sector who declared themselves as homosexuals. The interviews were analyzed using the discourse analysis technique developed by Michel Foucault. We found that some homosexual workers discriminate other homosexuals in their workplace. However, we observed that discrimination against homosexuals is considerably stronger and more often found in the discourse of the interviewees. It may occur because any sort of identity categorization serves as a power device (re) producer of values and discourses that reassembles the power relations already established in society. It was found that when homosexuals interviewed exhibit strong discrimination and repulsion to other homosexuals who are more Effeminate they intend a double movement which aims: I. reaffirm that this feature is in all homosexuals and that the effeminacy characteristic makes them inferior human beings within the range socially established, thus reinforcing the idea of homosexual identity, and 2 . that they, the respondents, are not inferior people because they do not have this identity characteristic.

\section{KEYWORDS}

Heterosexism; Heteronormativity; Homosexuals; Discrimination; Labor relations.

\section{(RE)PRODUCCIÓN DE HETEROSEXISMO Y HETERONORMATIVIDAD EN RELACIONES LABORALES: LA DISCRIMINACIÓN CONTRA LOS HOMOSEXUALES POR PARTE DE HOMOSEXUALES}

\section{RESUMEN}

En este artículo se estudia la posible existencia de discriminación en el trabajo contra los homosexuales practicados por los homosexuales. Inicialmente los 
estudios se analizaron Brasil y de América que implica el estudio de la discriminación contra los homosexuales en el lugar de trabajo. También se presentaron los conceptos de heterosexismo y heteronormatidad, así como sus efectos sobre la discriminación de los homosexuales, y la relación de estos conceptos para el diseño de la identidad homosexual. La investigación fue cualitativa y como instrumento de recolección de datos utilizó una entrevista seme-estructurada dividida en dos grandes bloques de preguntas. El primer bloque trata de comprender la historia de vida de cada sujeto y la forma en que se ocupa de su sexualidad en el entorno social en el que se inserta. El segundo bloque está directamente relacionado con la historia y la experiencia de los trabajadores profesionales. Hemos entrevistado a ocho trabajadores de la empresa de servicios del sector público y mixto gay. Las entrevistas fueron analizadas mediante la técnica de análisis del discurso (AD), desarrollado por Michel Foucault. Llegamos a la conclusión de que los homosexuales tienen prejuicios y la discriminación contra los homosexuales en el lugar de trabajo. Se encontró que la discriminación contra los homosexuales es algo que está presente en el discurso de los entrevistados, ya que se materializan las actitudes prejuiciosas hacia otros homosexuales, por ejemplo, no salir a la calle con la gente afeminados. Esto se debe a que toda identidad clasificación actúa como un dispositivo de poder (re)producción de valores y discursos que se manifiestan las relaciones de poder establecidas en la sociedad. Se encontró que cuando los homosexuales presentan una fuerte discriminación entrevistados y repulsión otros homosexuales que son más afeminados sujetos tienen la intención, mientras que un doble movimiento que tiene por objeto: I. reafirmar que esta característica se encuentra en todos los homosexuales del afeminamiento característica que los seres inferiores dentro del rango establecido hace sociales, lo que refuerza la idea de la identidad homosexual, y 2. que los encuestados no son personas inferiores, tienen esta identidad característica.

\section{PALABRAS CLAVE}

Heterosexismo; Heteronormatividad; Homosexuales; Discriminación; Relaciones laborales.

\section{REFERÊTCIAS}

BADGETT, M. V. L. The wage effects of sexual orientation discrimination. Industrial and Labor Relations Review, v. 48, n. 4, p. 726-739, I995.

BARBOSA, L. O consumo nas ciências sociais. In: BARBOSA, L.; CAMPELL, C. Cultura, consumo e identidade. Rio de Janeiro: Fundação Getulio Vargas, 2006. p. 2I-46. 
CAIN, R. Stigma management and gay identity development. Social Work, v. 36, p. 67-73, I99I. ECCEL, C. S.; FLORES-PEREIRA, M. T. A inserção da "diversidade" homossexual em uma livraria de shopping Center: um estudo crítico. In: ENANPAD, 32., 2008, Rio de Janeiro. Trabalhos apresentados. Rio de Janeiro: Anpad, 2008.

ELLIS, A. L.; RIGGLE, D. B. The relation of job satisfaction and degree of openness about one's sexual orientation for lesbians and gay men. Journal of homosexuality, v. 30, n. 2, p. 75-85, I996. ERIBON, D. Reflexões sobre a questão gay. Tradução Procopio Abreu. Editor José Nazar. Rio de Janeiro: Companhia de Freud, 2008.

FERREIRA, R. C.; SIQUEIRA, M. V. S. O gay no ambiente de trabalho: análise dos efeitos de ser gay nas organizações contemporâneas. In: ENANPAD, 3I., 2007, Rio de Janeiro. Trabalhos apresentados. Rio de Janeiro: Anpad, 2007.

FOUCAULT, M. História da sexualidade II: O uso dos prazeres. Rio de Janeiro: Edições Graal, I984. FOUCAULT, M. História da sexualidade III: O cuidado de si. Rio de Janeiro: Edições Graal, I985. FOUCAULT, M. História da sexualidade I: A vontade de saber. Rio de Janeiro: Edições Graal, I988. FOUCAULT, M. As palavras e as coisas. São Paulo: Martins Fontes, I999.

FOUCAULT, M. A arqueologia do saber. Rio de Janeiro: Forense Universitária, 2002.

FOUCAULT, M. A ordem do discurso. São Paulo: Edições Loyola, 2003.

FOUCAULT, M. Ética, sexualidade, política. Rio de Janeiro: Forense Universitária, 2004.

GAGNON, J. H. Uma interpretação do desejo: ensaios sobre o estudo da sexualidade. Rio de Janeiro: Garamount, 2006.

GREEN, J. N. Além do carnaval: a homossexualidade masculina no Brasil do século XX. São Paulo: Editora Unesp, 2000.

GREENHAUS, J. H.; PARASURAMAN, S.; WORMLEY, W. M. Effects of race on organizational experiences, job performance evaluations, and career outcomes. Academy of Management Journal, v. 33, p. 64-86, I990.

GUIMARÃES, C. D. O homossexualismo visto por entendidos. Rio de Janeiro: Garamont, 2004.

HASLOP, C.; HILL, H.; SCHIMIDT, R. A. The gay lifestyle - spaces for a subculture of consumption. Marketing Intelligence \& Planning, v. I6, n. 5, p. 318-326, I998.

HEREK, G. M. Stigma, prejudice, and violence against lesbians and gay men. In: GONSIOREK, J. C.; WEINRICH, J. D. Homosexuality: research implications for public policy. Newbury Park: Sage, I99I, p. 60-80.

HEREK, G. M. The social context of hate crimes: notes on cultural heteroxism. In: HEREK, G. M.; BERRIL, K. T. Hate crimes: confronting violence against lesbians and gay men. Newburry: Sage, I992, p. 89-IO4.

HEREK, G. M. Psychological perspective on lesbian and gay issues: stigma and sexual orientation. California: Sage, I998.

IRIGARAY, H. A. Políticas de diversidade nas organizações: uma questão de discurso? In: ENANPAD, 3I., 2007, Rio de Janeiro. Trabalhos apresentados. Rio de Janeiro: Anpad, 2007 a.

IRIGARAY, H. A. Estratégia de sobrevivência dos gays no ambiente de trabalho. In: ENANPAD, 3I., 2007, Rio de Janeiro. Trabalhos apresentados. Rio de Janeiro: Anpad, $2007 \mathrm{~b}$.

KATES, S. The protean quality of subcultural consumption: an ethnographic account of gay consumers. Journal of Consumer Research, v. 29, p. 383-399, 2002.

KINSEY. A. Sexual behavior in the human male. Indiana: Indiana University Press, I948. 
LOURO, G. L. Um corpo estranho: ensaios sobre sexualidade e teoria quer. Belo Horizonte: Autêntica, 2004 .

LOURO, G. L. Gênero, sexualidade e educação: uma perspectiva pós-estruturalista. Petrópolis: Vozes, 2008.

LYONS, H. Z.; BRENNER, B. R.; FASSINGER, R. E. A multicultural test of the theory of work adjustment: investigating the role of heterosexism and fit perceptions in the job satisfaction of lesbian, gay, and bisexual employees. Journal of Counseling Psychology, v. 52, n. 4, p. 537-548, 2005. MCCRAKEN, G. The long interview. Canada: Sage, I988.

MEYER, I. H. Minority stress and mental health in gay men. Journal of Health Sciences and Social Behavior, v. 36, p. 38-56, I995.

MISKOLCI, R. A teoria queer e a questão das diferenças: por uma analítica da normalilzação. In: CONGRESSO DE LEITURA DO BRASIL, I6., 2007, Campinas. Anais... São Paulo: Unicamp, 2007. NUNAN, A. Homossexualidade: do preconceito aos padrões de consumo. Rio de Janeiro: Caravansarai, 2003.

PEREIRA, C. A. Messeder. O impacto da AIDS, a afirmação da "cultura gay" e a emergência do debata em torno do "masculino" - fim da homossexualidade? In: RIOS, L. F. et al. Homossexualidade: produção cultural, cidadania e saúde. Rio de Janeiro: Abia, 2004, p. 52-62.

PINO, N. P. A teoria queer e os intersex: experiências invisíveis de corpos des-feitos. Cadernos Pagu, v. 28, p. I49-I74, jan./jun. 2007.

POCAHY, F. Um mundo de injúrias e outras violações. Reflexões sobre a violência heterossexual e homofóbica a partir da experiência do CRDH rompa o silêncio. In: POCAHY, F. Rompendo o silêncio: homofobia e heterossexismo na sociedade contemporânea. Políticas, teoria e atuação. Porto Alegre: Nuances, 2007.

RAGINS, B. R.; CORNWELL, J. M. Pink triangles: antecedents and consequences of perceived workplace discrimination against gay and lesbian employees. Journal of Applied Psychology, v. 86, n. 6, p. I244-126I, $200 \mathrm{I}$.

RIOS, R. R. O conceito de homofobia na perspectiva dos direitos humanos e no contexto dos estudos sobre preconceito e discriminação. In: POCAHY, F. Rompendo o silêncio: homofobia e heterossexismo na sociedade contemporânea. Políticas, teoria e atuação. Porto Alegre: Nuances, 2007. SAWAIA, B. B. Identidade: uma ideologia separatista? In: SAWAIA, B. B. As artimanhas da exclusão: análise psicossocial e ética da desigualdade social. Petrópolis: Vozes, 200 I.

SCOTT, J. Gênero: uma categoria útil de análise histórica. Educação e Realidade, Porto Alegre, v. I6, n. 2, p. 5-22, jul./dez. I990.

SCOTT, J. O enigma da igualdade. Estudos Feministas, Florianópolis, v. I3, n. I, p. II-30, jan./abr. 2005. SILVA, A. S. Marchando pelo arco-íris da política: a Parada Orgulho LGBT na construção da consciência coletiva dos movimentos LGBT no Brasil, Espanha e Portugal. 2006. Tese (Doutorado em Psicologia Social)-Pontifícia Universidade Católica de São Paulo, São Paulo, 2006.

SIQUEIRA, M. V. S.; FERREIRA, R. C.; ZAULI-FELLOWS, A. Gays no ambiente de trabalho: uma agenda de pesquisa. In: ENANPAD, 30., 2006, Bahia. Trabalhos Apresentados. Salvador: Anpad, 2006.

SMITH, N. G.; INGRAM, K. M. Workplace heterosexism and adjustment among lesbians, gay, and bisexual individuals: the role of unsupportive social interactions. Journal of Counseling Psychology, v. 5I, n. I, p. 57-67, 2004 . 
SWAIN, T. N. Para além do binário: os queers e o heterogêneo. Gênero, Niterói, v. 2, n. I, p. 87-98, 2. sem. 200I.

TREVISAN, J. S. Devassos no paraíso: a homossexualidade no Brasil, da colônia à atualidade. 5. ed. Rio de Janeiro: Record, 2000.

TRIANDIS, H. C.; KUROWSKI, L. L.; GELFAND, M. J. Workplace diversity. In: TRIANDIS, H. C.; DUNNETTE, M. D.; HOUGH, L. M. Handbook of industrial and organizational psychology. Palo Alto: Consulting Psychologists Press, I994.

WALDO, C. R. Working in a majority context: a structural modelo of heteroxism as minority stress in the workplace. Journal of Counseling Psychology, v. 46, p. 218-232, I999. 